\title{
O olhar saturnino de António Lobo Antunes em Que farei quando tudo arde?
}

\author{
Maria Cristina Chaves de Carvalho \\ (Universidade Federal Fluminense)
}

\section{RESUMO}

Este artigo propõe uma articulação de teorias sobre o barroco e o neobarroco, relacionando-as às experiências estéticas da cultura ocidental e ao romance português contemporâneo. O motivo da melancolia como tema e como procedimento de escrita é retomado, considerando-se a meditação saturnina observada na gravura de Dürer, Melancolia, entendida por João Adolpo Hansen como a "alegoria do conhecimento finito", cuja contemplação se destina aos objetos que se assemelham às ruínas. O culto barroco das ruínas pode ser compreendido através do "fragmento significativo", isto é, do estilhaço que, de acordo com a ótica benjaminiana, "é a matéria mais nobre da criação barroca". É essa contemplação das coisas que se quer investigar na contemporaneidade, a partir das personagens de António Lobo Antunes, enfatizando o olhar melancólico de Paulo - personagem do romance Que farei quando tudo arde? -, imerso num ambiente familiar onde não se identifica, consciente da sua fragilidade diante da vida e atormentado com a idéia da morte.

PALAVRAS-CHAVE: romance português contemporâneo; António Lobo Antunes; neobarroco

\section{ABSTRACT}

This article proposes an articulation of theories on Baroque and Neo-Baroque, relating them to the aesthetic experiences of the Occidental culture and to the contemporary Portuguese novel. The reason of melancholy as a theme and as a procedure of writing is resumed, considering the saturnine meditation observed on Dürer's print, Melancolia, understood by João Adolpo Hanses as the "allegory of the finite knowledge", whose contemplation leads to the objects which resemble to the ruins. The Baroque worship of the ruins may be understood through the "significant fragment", in other words, the fragment that, according to Walter Benjamin's view, "is the noblest material of the Baroque creation". This is the contemplation of the things to be investigated in the contemporaneity, based on António Lobo Antunes's characters, emphasizing Paulo's melancholy eye - a character from the novel Que farei quando tudo arde? - embedded in a familiar environment where he does not get identified with, aware of his fragility in face of life and tormented by the idea of death.

KEYWORDS: portuguese modern novel; António Lobo Antunes; neobaroque 
O barroco é uma arte de deslocamentos, semelhante a um espelho em que, constantemente, podemos ver a nossa identidade em mudança.

Carlos Fuentes $^{1}$

Este artigo propõe uma articulação de teorias sobre o barroco e o neobarroco, com a apropriação às experiências estéticas da sociedade ocidental atual, permitindo-se associar a essa perspectiva o romance português contemporâneo. Para nós, as teses de Severo Sarduy e de Walter Benjamin viabilizam uma apuração analítica de algumas obras de ficção que vêm sendo publicadas recentemente, investigando a possível existência de uma prática narrativa barroca, recuperada na atualidade através da vertente neobarroca.

$\mathrm{Na}$ segunda metade do século XX, a revitalização do Barroco surge como um meio de expressão das manifestações artísticas contemporâneas a partir de uma proposta de autores latino-americanos, entre os quais Lezama Lima, Alejo Carpentier e Severo Sarduy, este último autor de Barroco, obra que teoriza uma nova vertente estética denominada "neobarroco". ${ }^{2}$ No prefácio a Fugados, de Lezama Lima, Haroldo de Campos afirma que "o furioso neobarroco lezamesco é uma forma jubilosa de atualizar - repristinar - o passado na recepção reconfiguradora do presente" (CAMPOS in LIMA, 1993, p. 10), o mesmo que faz o discípulo de Lezama, Severo Sarduy, que é considerado o "monge da religião chamada Lezama" (CAMPOS in LIMA, 1993, p. 10).

No livro citado, Sarduy desenvolve uma tese que investiga a arte barroca, e afirma que é necessário reconhecer a importância de duas teorias dos séculos XVI e XVII: a primeira, de Galileu, relativa ao círculo, e a segunda, de Kepler, o qual sugere uma mudança de ordem cosmológica, substituindo o paradigma do círculo (ícone da forma perfeita) pela figura da elipse. Essa concepção do plano geométrico, isto é, a transferência da visão circular para a elíptica, disseminada para o campo simbólico, vai permitir que se tenha uma leitura isomórfica da representação de mundo refletida na ciência e nas artes em geral. Sarduy esclarece que:

[...] presentemente a figura matriz já não é o círculo, de centro único, radiante, luminoso, paternal, mas a elipse, que opõe a este foco visível um outro foco igualmente activo, igualmente real, mas obturado, morto, noturno, centro cego, reverso do yang solar germinador: ausente. (SARDUY, 1988, p. 57-58).

De acordo com essa ótica, a elipse representa o descentramento, a perturbação do círculo, e a arte assume a mesma complexidade que se reflete nessa tese. Em relação à literatura, entendemos que não há mais espaço para a simetria perfeita ou para o antropocentrismo, parâmetros que regulavam a produção cultural do renascimento, cuja arte se apresentava ordenada, procurando expressar a harmonia do homem e do mundo. Por outro lado, o barroco se caracterizava pelo desequilíbrio e pela paixão porque naquele período havia se formado uma nova consciência cósmica, provinda de uma noção de espaço infinito e de um universo descentrado.

Para a especialista na obra de Severo Sarduy, Irlemar Chiampi, a relação entre barroco e modernidade parte do conceito de barroco atemporal, identificado como uma forma que reaparece para ir de encontro ao espírito clássico renascentista. Chiampi cria uma imagem inusitada do barroco, ao afirmar que este é o "morto que continua falando" (CHIAMPI, 1998, p. 17), e 
enfatiza que esse é o caso específico de uma troca em que o passado conversa com o presente através de fragmentos e ruínas. Dessa maneira, a autora introduz o barroco nesse grande debate relativo à literatura e à modernidade 3 :

O barroco seria, pois, uma reciclagem de formas, a energização de materiais descartáveis, cujo primeiro momento de evidência como fato cultural ocorreu no século XVII e ocorrerá sempre que o discurso literário re-produza o imaginário da ciência, manejando seus enunciados (seus fragmentos) como se fossem metáforas. É inevitável reconhecer neste ponto a afinidade de Sarduy com Walter Benjamin, quem toma o barroco como 'origem', como fragmento, liberado do processo histórico e do encadeamento causal, que 'emerge do vir-a-ser e da extinção'; [...] o cenário barroco é o espaço da alegoria, do manejo dos fragmentos que dizem o 'outro' na ágora do texto. (CHIAMPI, 1998, p. 62-63).

Os romances de António de Lobo Antunes não buscam a totalidade, mas destacam o fragmento e apontam para as ruínas. Evidenciam o estilhaçamento do sujeito e narram a metamorfose da subjetividade na presença de ruínas, assim como Walter Benjamin, ao pensar, de acordo com Seligmann-Silva, "essa nova prática de escritura do passado a partir das ruínas de seu presente" (SELIGMANN-SILVA, 2008, p. 50). É dessa maneira que o culto barroco das ruínas pode ser compreendido através do "estilhaço" que, segundo Benjamin, "é a matéria mais nobre da criação barroca" (BENJAMIN, 1984, p. 200).

O romance Que farei quando tudo arde?, de António Lobo Antunes, publicado em 2001, remete a um verso de Sá de Miranda, extraído do soneto do poeta - incipit: "Dezarrezoado amor dentro em meu peito" (MIRANDA, 1937, p. 310) -, uma alusão ao conflito entre o amor e a razão, poema em que o sujeito lírico vivencia um amor abrasador, isto é, que inflama, excita e arrebata ${ }^{4}$. No soneto de Sá de Miranda, há, de um lado, o amor que se mostra autoritário, forte e destruidor, enquanto que, de outro, a razão é paciente e vigilante. Essa tensão cantada pelo poeta parece afirmar a impotência de todos aqueles que amam desarrazoadamente, e que culmina com o que se pode depreender do verso que encerra o soneto: "Que farei quando tudo arde?" 5.

Desde o título do romance percebemos que há uma proposta ambígua do autor em relação ao seu texto, pois a polissemia é encontrada no verbo "arder", hoje com o significado muito mais ligado ao fogo e à destruição, mas que não deixa de ser usado com o mesmo sentido de paixão referido no soneto de Sá de Miranda. Como diz Compagnon, "a porta de entrada de um livro é seu título, encimado com o nome do autor, como se fosse um troféu". (COMPAGNON, 1996, p. 71). Nesse romance de António Lobo Antunes encontramos o amor e o desconcerto do mundo, marcados sob o signo da melancolia. Portanto, esse título que interroga pode vir a sugerir uma pergunta que o escritor contemporâneo faz a si mesmo, procurando responder através de sua escrita, com a elaboração de uma poética. O quê ou sobre o quê escrever, como narrar em um mundo onde tudo "arde"? De acordo com Eduardo Lourenço:

“a poética dos romances de António Lobo Antunes não é propriamente naturalista, a não ser pelo lado darwiniano que ela tem, por ver a vida como um combate no interior dela própria, 
como um combate feroz, sem fim e sem saída. Mas não se limita a isso. É uma imagem da realidade portuguesa com tudo o que nós não víamos se essa obra não existisse com o que estava submerso a todos os níveis, aos níveis do relacionamento social, do erotismo, e sobretudo o que estava imerso entre razão e loucura." (LOURENÇO, 2003, p.354).

O romance objeto de análise relata o drama de uma família, no qual se representa a vida e a morte do travesti Carlos, pai de Paulo, metamorfoseado em Soraia, e envolve outras personagens, especialmente, Paulo e sua mãe Judite, assim como Rui, marido de Soraia. São essas vozes que vão construir a história, mostrando as mudanças que sofrem as personagens do romance. $\mathrm{O}$ andrógino Carlos-Soraia passa a desvendar a "matriz dupla de uma existência" (SEIXO, 2002, p. 428), porque é uma personagem que transita de um gênero a outro, caracterizando-se pelo erotismo que dele emana, e encaminhando questões ontológicas e sociais que inevitavelmente ampliam sua vivência em termos não somente ligados à sexualidade.

Desse modo, entendemos que o artifício utilizado pelo autor, relativo à sexualidade e à experimentação de uma existência duplicada, pode ser aproximado da tese de Sarduy, por acreditar que "o barroco será extravagância e artifício, perversão de qualquer ordem fundada, equilibrada: moral" (SARDUY, 1988, p. 51), tal como a personagem Soraia que, de um lado, recupera a figura barroca em seus exageros, cores e brilhos e, de outro, como margem, indica uma recusa às totalidades e aos modelos institucionalizados, sugerindo mudanças. Desse modo, a negatividade que permeia os relatos das personagens pode ser vista como uma proposta de mudança, destacada através do olhar de Paulo acerca de Carlos-Soraia:

Agora que meu pai morreu acho que comecei a procurá-lo mas não sei. Não sei. Dou voltas e voltas e a resposta é não sei. Tudo me parece tão difícil, tão complicado, tão esquisito: um palhaço que ao mesmo tempo era homem e mulher ou umas vezes homem e outras mulher ou umas vezes uma espécie de homem e outras uma espécie de mulher comigo a pensar - Como é que o chamo?

[...] viro a cabeça do avesso e não sei (ANTUNES, 2001, p. 109).

Sarduy utiliza o termo travestimento como metáfora para a escritura, entendido como uma indefinição do sujeito que não quer ser mulher, mas que almeja ser simultaneamente os dois gêneros. O gesto de travestir está relacionado ao fato de simular ser outro: ser mulher apenas na aparência. No romance em análise, essa experiência de simulação pode ser também encontrada no caráter ambíguo do texto, pois sua tessitura vai sendo apresentada de forma indefinida - tanto quanto o corpo de Carlos -, além de associar a idéia de erotismo ao prazer que a leitura do texto proporciona ao leitor.

Antonio Lobo Antunes lança um novo olhar para a ficção portuguesa contemporânea. Em seu processo de criação expõe toda a construção do tecido literário, busca incessantemente o "regresso a si mesmo" (SARDUY, 1988, p. 54), demonstrando, ao mesmo tempo, uma preocupação com a descoberta do outro que se mostra ou que é visto em imagem distorcida ou anamórfica. $\mathrm{O}$ autor interroga a luz e a sombra, como no barroco, ou como na 
estética neobarroca, porque não contempla uma obra acabada, mas sim uma obra aberta (de acordo com os princípios de Heinrich Wölfflin - as formas abertas do barroco), cuja estrutura apresenta lacunas a serem (ou não) preenchidos pelo leitor. ${ }^{6}$

A epígrafe que introduz o romance, de Epifâneo Salamina, anuncia a abertura de uma escrita que se configura na busca de si através do outro, além de evidenciar a escamoteação, a dispersão do ser e consequentemente a mudança: "Eu sou tu e tu és eu; onde estás eu estou e em todas as coisas me acho disperso. Seja o que for que encontres é a mim que encontras: e, ao encontrares-me, encontras-te a ti mesmo.". Logo, o leitor desse romance começa a percorrer o seu interior, conhece os bastidores do teatro de revista de Soraia, observa a troca de papéis de suas personagens e a mudança na linguagem, que é permeada pelo olhar melancólico a divagar pelo passado.

Retornando aos estudos sobre o barroco, encontramos um esclarecimento de Leandro Konder sobre a retomada do drama barroco na tese de Walter Benjamin. Konder afirma que em Origem do drama barroco alemão Benjamin "não estava se ocupando de 'literatura morta'; estava, na realidade, promovendo uma revisão no próprio conceito de 'barroco' tradicionalmente utilizado pelos historiadores da literatura.". (KONDER, 1999, p.34).

O drama barroco alemão, Tranerspiel, aceita a conjugação de duas expressões: Spiel, que significa jogo ou representação, e Traner, que se traduz como luto. Portanto, deve ser compreendido como uma estrutura que permite a simultaneidade do lúdico e do luto numa mesma representação, ou seja, um drama a ser encenado, um teatro que pode revelar a natureza conflitante do homem barroco, além de exibir a ostentação e os artifícios tão em voga no período. De modo conciso, Konder diz que “o ‘drama barroco' pressupõe espectadores inseguros, submergidos na iminência do movimento da história, condenados a refletir melancolicamente sobre problemas insolúveis" (KONDER, 1999, p. 35).

Nesse sentido procuramos refletir sobre o barroco e a modernidade (ou contemporaneidade), investigando se o sentimento de melancolia atravessa ambas as épocas. A gravura de Dürer, Melancolia, é entendida por João Adolfo Hansen como a "alegoria do conhecimento finito", cuja contemplação se destina aos objetos que se assemelham às ruínas. ${ }^{8}$ Nessa imagem, analisada como texto, verificamos a representação da meditação saturnina personificada na figura de uma mulher, pois a Melancolia mantém um olhar fixo numa atitude que pode exprimir uma pausa para meditação ou, talvez, uma divagação acerca de sua própria escrita. Segundo Hansen:

A Melancolia I, gravura de Dürer datada de 1512, é bem a alegoria dessas alegorias numéricas e geométricas, figurando o tipo saturnino ou o humor sombrio condenado a ficar aquém da contemplação angélica. A personagem sentada com o rosto apoiado na mão, olhar distante, era pose convencional da tristeza e do luto na arte antiga, e da meditação, na arte carolíngia e miniaturas medievais. Utilizada para figurar a melancolia, assume valor de emblema: alegoria do conhecimento finito. (HANSEN, 2006, p.147).

O processo de criação que abriga a melancolia é tecido a partir do fragmento, uma poética marcada pelo desencanto, em virtude da impossibilidade de total compreensão do mundo, logo, o fragmento se encontra na base de toda sensibilidade melancólica. É a certeza do caráter 
fugidio do tempo, da efemeridade da vida, dos seres e dos objetos, o que leva o melancólico a ser arrancado do continuum do tempo - ou da história - e o torna incapaz de recompor-se.

É dessa maneira que o fragmento confere à melancolia o caráter de alegoria. A recuperação da melancolia, como base ético-estética e como um recurso que busca fixar um método de criação, tendo em vista uma tendência ao olhar melancólico em algumas narrativas contemporâneas, é uma perspectiva a ser considerada nos romances de António Lobo Antunes, nos quais a "ética da memória implica um duplo ato: por um lado a destruição da falsa ordem das coisas e, por outro, a construção de um novo espaço mnemônico" (SELIGMANN-SILVA, 2008, p. 49).

Em Que farei quando tudo arde?, encontramos personagens melancólicas, a presença de uma luz saturnina, um cenário que pretende induzir o leitorespectador a uma leitura alegórica do mundo. Dentre as personagens, a voz predominante na narrativa é a de Paulo, que pode ser chamado de António ou de Antunes, "coincidindo" com o nome do autor. A perspectiva narrativa de Paulo traduz a sua perplexidade diante do transitório e do contingente, como se observa na seguinte citação: "o mundo a gente põe-se a pensar e a vida tão insólita deu em apequenar-se repara, o universo um pingo de torneira que continha tudo, a casa, os malmequeres" (ANTUNES, 2001, p. 205).

Essa voz que prevalece ao longo da narrativa é a mesma que escreve a história, ou a sua história dos outros, porque, ao negar, afirma a sua escrita. Paulo acredita que somente através de sua recordação do passado, a partir das memórias do pai, da mãe e da mulher poderá voltar a encontrá-los, encontrando a si mesmo. Esse processo de escrita do narrador-personagem Paulo pode ser identificado através do seguinte fragmento do texto, que expõe a sua organização:

Não se trata de vontade de escrever, já basta o que me obrigam a escrever no emprego para ter paciência de gastar os serões a matar a cabeça com uma caneta e um caderno, mas é a única forma que tenho de tentar encontrar-vos

[...] de maneira a libertar um ângulo da mesa, e então soltar os cães das palavras na esperança que algumas delas, vibrando a cauda de uma consoante alegre, vos descubra vivos

como se pudessem estar vivos

sob os escombros de anos e anos e tanto entulho de recriminações, zangas, gencianas, na esperança que alguma delas principie a esgravatar os fragmentos de caliça do passado que eu imaginava em descanso para sempre e nisto mais palavras agruparem-se, agitadas, contentes, desprendendo-se da trela do aparo, eu a aproximar o nariz do papel buscando-vos submersas nas linhas, uma vozita débil

- Paulo

que penso reconhecer apesar dos caprichos da memória que distorce e apaga (ANTUNES, 2001, p. 457-458).

Como num entrelaçar de diversas histórias, as personagens de Lobo Antunes recuperam o passado pela via da memória, ou, como afirma Jean Marie Gagnebin, pela "busca das analogias e das semelhanças entre o passado e o presente" (GAGNEBIN, in BENJAMIN, 1994, p. 15). Neste movimento, tais personagens não reencontram propriamente o passado, "mas a presença do passado no presente e o presente que já está lá, prefigurado no passado, ou 
seja, uma semelhança profunda, mais forte do que o tempo que passa e se esvai sem que possamos segurá-lo" (GAGNEBIN, in BENJAMIN, 1994, p. 15-16). Portanto, nesse romance, os relatos baseados em memórias delineiam a construção das personagens e parecem dar origem a uma forma nova de escrita, capaz de libertar a própria estrutura narrativa. Paulo, ao escrever, inventa histórias:

Se pudéssemos conversar não importa onde a casa da praia, os Anjos, o Príncipe Real, a cave

um lugar onde fôssemos não os fantasmas de agora mas as pessoas de dantes, fantasmas vocês que perdi e fantasma eu que os procuro entre sombras falando-vos como falam os mortos e respondendo palavras minhas, não vossas, o que espero que digam sabendo que não diriam desse modo, se pudessem contar-me o que não conheço e talvez prefira não conhecer, o que sucedeu antes do meu nascimento ou quando era pequeno demais para entender que sucedera e apenas me permito inventar, conforme as cartas antigas inventam o passado não me explicam acerca dele, inventam (Antunes, 2001, p.477).

$\mathrm{Na}$ seguinte cena, o olhar fixo de Paulo para o teto vem sugerir uma aparente hesitação entre dois estados - o sono e a vigília -, como se ele estivesse aprisionado, contemplativo diante das coisas e entre ruínas. Ao estado letárgico da personagem, somam-se os efeitos da droga, proporcionados pelo uso de heroína:

A gente põe-se a pensar e a vida tão esquisita, ainda há dias ou seja há bocadinho estava internado no hospital, o psicólogo se não desenhas uma casa uma família e uma árvore digo ao médico e não tens alta nunca e de repente

sem transição nenhuma

eis-me aqui na marquise dos Anjos a empurrar o êmbolo da seringa para o interior da pele, à medida que o êmbolo se aproxima da agulha transformo-me num balão de gás encostado ao tecto com o seu cordelzinho pendurado

o mesmo de que me servi para encontrar a veia ao apertá-lo no braço

só que daqui a duas horas o gás começa a fugir e desço até encontrar a dona Helena a passar ferro, o senhor Couceiro na poltrona e o psicólogo a observar a casa, a família e a árvore. (ANTUNES, 2001, p. 203).

Verificamos que a atitude deveras pessimista da personagem vai ser convertida numa escrita que se aproxima muito de seu estado psíquico. Paulo regressa do "delírio" provocado pela injeção da droga para encontrar o sentimento de melancolia, porque, livre dos efeitos causados pela heroína, volta novamente à consciência acerca da condição humana, da efemeridade do corpo e da transitoriedade da vida:

[...] e eu a voar no tecto da marquise com a ajuda da seringa, o psicólogo o que é isso aí, eu a explicar que sou eu a voar no tecto da marquise com o cordelzinho de engrossar as veias a 
tombar da manga, o psicólogo qual cordelzinho, eu se vier comigo a Chelas e me emprestar dinheiro voamos ambos por cima dos plátanos de mistura com os pombos, o psicólogo a queixar-se ao médico este hoje afiança que voa e o médico se voa corto-lhe as asas num instante descanse, chamou o enfermeiro dê aqui um salto Vivaldo, e mal o senhor Vivaldo anda à minha procura doutor, o médico o amigo à minha frente deu-lhe para voar imagine

[...] a casa, a família quer-se dizer eu sozinho, a árvore que desejaria um cedro e apenas um novelo de riscos embora não fizesse mal dado que não andamos em Belas Artes rapaz, o enfermeiro acabaram-se os passeios pelo ar és uma lesma agora, [...] o médico satisfeito o canário ficou-se, ainda agitei os braços e qual quê, nem estremeci no colchão, a ruça para o enfermeiro matou-o não matou senhor Vivaldo, um plátano veio espreitar-me da janela e escapou-se

tão insólita a vida (ANTUNES, 2001,

p. 204-205).

O romance Que farei quando tudo arde? apresenta o tema da identidade, põe ao alcance dos leitores as emoções de personagens intensas, possibilitando uma leitura que relacione essa mesma intensidade à obsessão do autor pela escrita, e esta, por esse motivo, exacerba, exagera e excede. Entendemos que o termo "discurso engenhoso" referido por Saraiva - com o intuito de mostrar a diferença de natureza entre discurso clássico e discurso engenhoso, isto é, barroco - pode ser aplicado ao texto de Lobo Antunes. Esse engenho pode ser identificado através da ambiguidade do texto literário, de suas personagens complexas, da polifonia, da superposição dos tempos e dos espaços. Enfim, toda essa "maquinaria" nos é revelada através das histórias inventadas por Paulo9. A certa altura, Paulo se revela fragilizado diante do desconcerto do mundo que o cerca e da perda afetiva:

Quando penso em mim penso naqueles artistas vestidos de chineses que colocam uma mesa no centro da pista, no tampo da mesa várias hastes de bambu, na extremidade de cada haste um prato que gira [...] outra haste, a da ponta que nenhum sorriso consegue suster, o meu pai morto, com a Sissi que não podia ser a Sissi, a Sissi em Espanha ou se calhar homem outra vez (ANTUNES, 2001, p. 513).

[...] sacudir a haste até recuperar pedacinhos, fragmentos, episódios sem nexo que a memória unia [...] se fosse capaz de deslocá-los em sentido contrário

Uma vida diferente, inventei tudo que tolice (ANTUNES, 2001, p.514).

Esse romance de António Lobo Antunes vem espelhar um mundo apático e vazio onde não há lugar para a esperança. O autor, mais do que contar uma história, arquiteta uma espécie de jogo lúdico nas suas narrativas, e desafia os leitores a persegui-lo. Nuno Júdice em "Os mapas do humano em António Lobo Antunes" cita o romancista: 
O que pretendo é transformar a arte do romance, a história é o menos importante [...] a intriga não me interessa, o que queria não é tanto que me lessem mas que vivessem o livro. As emoções são anteriores às palavras e o repto é traduzir essas emoções, tentar que as palavras 'signifiquem' essas emoções [...] Como fazem os poetas. (ANTUNES, in JÚDICE, 2003, p. 316. grifos nossos).

No romance em foco, entendemos que o autor, ao abordar o tema da identidade, utilizando-se da sexualidade simulada ou travestida dos sujeitos, realiza uma experimentação narrativa de maneira exuberante. Essa relação da construção de uma identidade - que parte de uma matriz dupla: Carlos-Soraia - pode revelar um estilo transgressivo que se caracteriza pelo artifício e por uma profusão linguística muito afim à vertente neobarroca. Dessa forma, é necessário lembrar que os fundamentos relativos aos estudos de Severo Sarduy sobre o barroco convergem para a consagração do "artifício" como procedimento encarregado de simular a força da teatralização da escritura.

$\mathrm{Na}$ arte barroca a imanência, a consciência da finitude da vida, o luto e a melancolia são temas que geralmente se apresentam. A melancolia é um sentimento que acompanhou o homem barroco e que parece desdobrar-se até a atualidade, porque nós a encontramos ainda hoje, não somente como tema, mas como importante procedimento da criação literária de alguns autores contemporâneos. Benjamin diz que "o luto é o estado de espírito em que o sentimento reanima o mundo vazio sob a forma de uma máscara, para obter da visão desse mundo uma satisfação enigmática", ressaltando que "a meditação é própria do enlutado" (BENJAMIN, 1984, p. 162-163).

Assim, o percurso traçado pelas personagens desse romance parece calcado numa constante investigação quanto ao sentido da vida, da história e da literatura, feita através de um mundo "que se abre ao olhar do melancólico" (BENJAMIN, 1984, p. 163), por isso, as suas personagens não conseguem alcançar no presente uma perspectiva para o futuro, pois veem apenas ruínas.

\section{NOTAS}

1. FUENTES, Carlos. Apud DANIEL, Claudio. Jardim de Camaleões: a poesia neobarroca na América Latina. São Paulo: Iluminuras, 2004.

2. De acordo com Haroldo de Campos, Lezama Lima é o "mestre cubano, espécie criolla de Mallarmé e Proust, numa só reencarnação hispano-falante, caldeada retrospectivamente no crisol luciferino de Don Luis de Góngora Y Argote”. Prefácio ao livro Fugados, de José Lezama Lima. In: LIMA, José Lezama. Fugados. São Paulo: Iluminuras, 1993.

3. Essa é a nossa opção, em função das diversas teorias coexistentes que não mais conseguem traduzir uma única verdade: não há distinção entre margem e centro; não há coletividade, não há adesão; não há normas e nem desvios. $\mathrm{Na}$ América Latina surge a vertente neobarroca (anos de 50), na década seguinte, é o momento do boom, que consagra o autor Alejo Carpentier e, dos anos 70 até a atualidade, é o período considerado como o pós-boom. Na década de 60, uma outra linha de estudos começa a ser desenhada nos Estados Unidos e também no Canadá, confluindo nos anos 80 para uma grande discussão entre os teóricos de arte sobre o entendimento do pósmoderno de acordo com uma perspectiva histórica. O grande questionamento diz respeito à ruptura ou continuidade do 
modernismo, em virtude da reflexão sobre os problemas que a exaustão do alto modernismo suscitou. A arte hoje comumente rotulada de pós-moderna tem procurado enfrentar tais problemas esteticamente e mesmo politicamente. Dentre os teóricos que abarcam a teoria sobre a pós-modernidade desde os anos 80, destacamos Andreas Huyssen, Frederic Jameson e Linda Hutcheon.

4. Soneto de Sá de Miranda: "Dezarrezoado amor, dentro em meu peito/ tem guerra com a razão. Amor, que jaz/ i já de muitos dias, manda e faz / tudo o que quer, a torto e a direito./ Não espera razões, tudo é despeito, / tudo soberba e força, faz, desfaz, / sem respeito nenhum, e quando em paz / cuidais que sois, então tudo é desfeito. / Doutra parte a razão tempos espia, / espia ocasiões de tarde em tarde, / que ajunta o tempo: em fim vem o seu dia. / Então não tem lugar certo onde aguarde / amor; trata treições, que não confia / nem dos seus. Que farei quando tudo arde? In: MIRANDA, Sá de. Obras Completas. Coleção de Clássicos Sá da Costa. Texto fixado, notas e prefácio pelo Prof. M. Rodrigues Lapa. Lisboa: Sá da Costa, 1937. 5. Em Portugal, a consagração do chamado dolce stil nuevo foi atribuída a Francisco Sá de Miranda (1481-1558). O poeta foi colaborador do Cancioneiro Geral e cultivou em língua portuguesa as formas constantes na referida coletânea, antes e também depois da sua opção pelo novo estilo, por aceitar a coexistência dos dois estilos. A importância da poesia de Sá de Miranda pode ser assegurada por Saraiva, ao afirmar que o Poeta "está na corrente que conduz ao Barroco peninsular, e torna-se um dos precursores do conceptismo seiscentista". In: SARAIVA, António José \& LOPES, Oscar. História da Literatura Portuguesa. 12. ed. Porto: Porto Editora, 1982, p. 260-261.

6. Obra aberta no sentido de estrutura aberta, segundo os princípios de Heinrich Wölfflin - as formas abertas do barroco. A propósito, diz o narrador de Ópera dos Mortos, de Autran Dourado: "Veja de vários ângulos e sinta, não sossegue nunca o olho, siga o exemplo do rio que está sempre indo, mesmo parado vai mudando. $O$ senhor veja o efeito, apenas sensação; veja a ilusão do barroco, mesmo em movimento é como um rio parado; veja o jogo de luz e sombra, de cheios e vazios, de retas e curvas, de retas que se partem para continuar mais adiante, de giros e volutas...". In: DOURADO, Autran. Uma poética de romance: matéria de carpintaria. Rio de Janeiro: Rocco, 2000, p.54.

7. GULAR, Ferreira. Sobre a arte barroca, fala Ferreira Gullar: "é só no século XIX que de fato se dá uma valorização do Barroco, que ele é resgatado como uma expressão estética válida e como um fenômeno estético de alta significação, porque até aí ele não tinha esse valor." In: "Barroco olhar e vertigem". O Olhar. Org. Adauto Novaes [et AL]. São Paulo: Companhia das Letras, 1988, p. 219.

8. Hansen diz que "Walter Benjamin demonstrou como Baudelaire lança mão da alegoria justamente devido a seu caráter convencional, como destruição do orgânico e extinção da aparência. Fazendo da alegoria a máquina-ferramenta da modernidade e pensando-a como antídoto contra o mito, ao mesmo tempo que a incorpora como método de escrita e de crítica, Benjamin a propõe como o outro da História.". In: HANSEN, João Adolfo. Alegoria. Construção e interpretação da metáfora. São Paulo: Editora Unicamp, 2006, p. 19. (gravura de Dürer, p.22).

9. No estudo de Saraiva intitulado "As quatro fontes do discurso engenhoso nos sermões do padre António Vieira", o autor afirma que "o essencial do barroco, no que se refere à literatura, reside justamente no 'discurso engenhoso' [...] discurso "quer dizer, antes de mais nada, encadeamento e desenvolvimento. A ordem do discurso não é forçosamente uma ordem lógica. As únicas 
regras a que a palavra não pode fugir são as da gramática. No discurso clássico, parece haver a obrigação de subordinar a gramática à lógica e dar um sentido às palavras.”. In: SARAIVA, António José.

O Discurso Engenhoso.São Paulo: Perspectiva, 1980, p. 8.

\section{REFERÊNCIAS BIBLIOGRÁFICAS}

ANTUNES, António Lobo. Que farei quando tudo arde?. 2a ed. Lisboa: Dom Quixote, 2001.

BENJAMIN, Walter. Origem do drama barroco alemão. Tradução, apresentação e notas: Sérgio Paulo Rouanet. São Paulo: Brasiliense, 1984.

Magia e Técnica, Arte e Política: ensaios sobre literatura e história da cultura. Tradução de Sérgio Paulo Rouanet, prefácio de Jeanne Marie Gagnebin. $7^{\text {a }}$. ed., São Paulo: Brasiliense, 1994.

CHIAMPI, Irlemar. Barroco e modernidade: ensaios sobre literatura latino-americana. São Paulo: Perspectiva, 1998.

COMPAGNON, Antoine. O trabalho da citação. Tradução de Cleonice P.B. Mourão. Belo Horizonte: UFMG, 1996.

DANIEL, Claudio. Jardim de Camaleões: a poesia neobarroca na América Latina. São Paulo: Iluminuras, 2004.

DOURADO, Autran. Uma poética de romance: matéria de carpintaria. Rio de Janeiro: Rocco, 2000.

GULLAR, Ferreira. "Barroco olhar e vertigem". O Olhar. Org. Adauto Novaes [et al]. São Paulo: Companhia das Letras, 1988.

HANSEN, João Adolfo. Alegoria. Construção e interpretação da metáfora. São Paulo: Editora Unicamp, 2006.

JÚDICE, Nuno. "Os mapas do humano em António Lobo Antunes". In: CABRAL, Eunice; JORGE, Carlos J. F.; ZURBACH, Christine (orgs.). A escrita e o mundo em António Lobo Antunes: Actas do Colóquio Internacional da Universidade de Évora. Lisboa: Dom Quixote, 2003, p. 313-319.

KONDER, Leandro. O marxismo da melancolia. $3^{\text {a }}$. ed. Rio de Janeiro: Civilização Brasileira, 1999.

LIMA, José Lezama. Fugados. Apresentação de Haroldo de Campos. Tradução de Josely Vianna Baptista. São Paulo: Iluminuras, 1993.

LOURENÇO, Eduardo. "Divagação em torno de Lobo Antunes". In: CABRAL, Eunice \& JORGE, Carlos J. F. \& ZURBACH, Christine (orgs.). A escrita e o mundo em António Lobo Antunes: Actas do Colóquio Internacional da Universidade de Évora. Lisboa: Dom Quixote, 2003.

MIRANDA, Sá de. Obras Completas. Coleção de Clássicos Sá da Costa. Texto fixado, notas e prefácio pelo Prof. M. Rodrigues Lapa. Lisboa: Sá da Costa, 1937.

SARAIVA, António José. O Discurso Engenhoso.São Paulo: Perspectiva, 1980.

SARAIVA, António José \& LOPES, Oscar. História da Literatura Portuguesa. Porto: Porto Editora, 12a . ed., 1982.

SARDUY, Severo. Barroco. Tradução de Maria de Lurdes Júdice e José Manuel de Vasconcelos. Lisboa: Veja Universidade, 1988.

SEIXO, Maria Alzira. Os romances de António Lobo Antunes. Lisboa: Dom Quixote, 2002.

SELIGMANN-SILVA, Márcio. Benjamin pensa a Educação. Revista Educação, São Paulo: Editora Segmento, 2008.

(Recebido para publicação em 30/06/2009, Aprovado em 23/07/2009) 